Annales Geophysicae (2003) 21: 1057-1069 (c) European Geosciences Union 2003

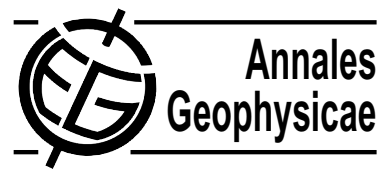

\title{
Observation of an unusual mid-stratospheric aerosol layer in the Arctic: possible sources and implications for polar vortex dynamics
}

\author{
M. Gerding ${ }^{1}$, G. Baumgarten ${ }^{2}$, U. Blum ${ }^{3}$, J. P. Thayer ${ }^{4}$, K.-H. Fricke ${ }^{3}$, R. Neuber ${ }^{1}$, and J. Fiedler ${ }^{2}$ \\ ${ }^{1}$ Alfred-Wegener-Institut für Polar- und Meeresforschung, Forschungsstelle Potsdam, Telegrafenberg A43, D-14473 Potsdam, \\ Germany \\ ${ }^{2}$ Leibniz-Institut für Atmosphärenphysik, Schloss-Straße 6, D-18225 Kühlungsborn, Germany \\ ${ }^{3}$ Physikalisches Institut, Universität Bonn, Nussallee 12, D-53115 Bonn, Germany \\ ${ }^{4}$ SRI International, Center for Geospace Studies, 333 Ravenswood Avenue, Menlo Park, CA 94025, USA
}

Received: 14 June 2002 - Revised: 11 October 2002 - Accepted: 15 October 2002

\begin{abstract}
By the beginning of winter 2000/2001, a mysterious stratospheric aerosol layer had been detected by four different Arctic lidar stations. The aerosol layer was observed first on 16 November 2000, at an altitude of about $38 \mathrm{~km}$ near Søndre Strømfjord, Greenland $\left(67^{\circ} \mathrm{N}, 51^{\circ} \mathrm{W}\right)$ and on 19 November 2000, near Andenes, Norway $\left(69^{\circ} \mathrm{N}, 16^{\circ} \mathrm{E}\right)$. Subsequently, in early December 2000, the aerosol layer was observed near Kiruna, Sweden $\left(68^{\circ} \mathrm{N}, 21^{\circ} \mathrm{E}\right)$ and Ny-Ålesund, Spitsbergen $\left(79^{\circ} \mathrm{N}, 12^{\circ} \mathrm{E}\right)$. No mid-latitude lidar station observed the presence of aerosols in this altitude region. The layer persisted throughout the winter 2000/2001, at least up to 12 February 2001. In November 2000, the backscatter ratio at a wavelength of $532 \mathrm{~nm}$ was up to 1.1, with a FWHM of about $2.5 \mathrm{~km}$. By early February 2001, the layer had sedimented from an altitude of $38 \mathrm{~km}$ to about $26 \mathrm{~km}$. Measurements at several wavelengths by the ALOMAR and Koldewey lidars indicate the particle size was between 30 and $50 \mathrm{~nm}$. Depolarisation measurements reveal that the particles in the layer are aspherical, hence solid. In the midstratosphere, the ambient atmospheric temperature was too high to support in situ formation or existence of cloud particles consisting of ice or an acid-water solution. Furthermore, in the year 2000 there was no volcanic eruption, which could have injected aerosols into the upper stratosphere. Therefore, other origins of the aerosol, such as meteoroid debris, condensed rocket fuel, or aerosols produced under the influence of charged solar particles, will be discussed in the paper. Trajectory calculations illustrate the path of the aerosol cloud within the polar vortex and are used to link the observations at the different lidar sites. From the descent rate of the layer and particle sedimentation rates, the mean downward motion of air within the polar vortex was estimated to be about $124 \mathrm{~m} / \mathrm{d}$ between 35 and $30 \mathrm{~km}$, with higher values at the edge of the vortex.
\end{abstract}

Key words. Atmospheric composition and structure (aerosols and particles; middle atmosphere composition

Correspondence to: M. Gerding

(gerding@iap-kborn.de) and chemistry) - meteorology and atmospheric dynamics (middle atmosphere dynamics)

\section{Introduction}

In the early 1960s, the first lidar observations of stratospheric aerosol were reported (Fiocco and Grams, 1964). Some years before, Junge et al. (1961) discovered a permanent layer of aerosol in the lower stratosphere, which is one of the four types of aerosols identified by extensive soundings of the stratosphere during the following years: (1) "background" aerosol, (2) volcanic aerosol, (3) smoke particles from fires, and (4) polar stratospheric clouds.

The background aerosol is formed by particles in the sub-micron range. Junge et al. (1961) observed particles smaller 0.1 micron diffusing upwards from the tropopause. The particle density decreased from about $100 \mathrm{~cm}^{-3}$ near the tropopause to $0.1 \mathrm{~cm}^{-3}$ at $7-10 \mathrm{~km}$ above. Particles larger 0.1 micron reach their maximum mixing ratio of about $1 \mathrm{~cm}^{-3}$ in the upper part of this region. This background aerosol layer is often called as "Junge layer". Particles in the micron-range and larger have been observed only occasionally (Junge et al., 1961). The background aerosol consists of heterogeneously condensed sulphuric acid droplets. Because of the correlation between the tropopause altitude and the Junge layer, the altitude of the background aerosol decreases polewards (Hofmann and Rosen, 1981).

Several months after the eruption of Mt. St. Helens, the background aerosol load increased by about a factor of 3 (Hofmann and Rosen, 1982). This aerosol was observed to be smaller in size than during times without volcanic disturbances. After the sedimentation of large ash particles, only volatile aerosols were found at and above $18 \mathrm{~km}$. Similar to the Junge aerosol, the volcanic aerosol consists mainly of sulphuric acid droplets. Above $26 \mathrm{~km}$ no enhancement of the aerosol content by the Mt. St. Helens eruption was observed by balloon-borne instruments (Hofmann and Rosen, 1982). The most recent volcanic eruption occurred 1991 at 
Mt. Pinatubo. Since 1996, no volcanic disturbance of the stratospheric aerosol load has been observed.

Polar stratospheric clouds (PSCs) are observed at high latitudes during winter and spring. This aerosol is found mainly below $30 \mathrm{~km}$ altitude. In general, PSCs consist of (solid) nitric acid trihydrate (NAT), ice crystals, or a supercooled ternary solution (STS) of sulphuric acid, nitric acid, and water. The appearance and spatial distribution of PSCs depends strongly on the ambient temperature. From lidar observations, several types of PSCs can be distinguished by their backscatter ratio $R$ and depolarisation $\delta$, which includes information about the phase of the particles. The backscatter ratio is defined as the ratio of the total (aerosol + molecules) to the molecular backscattering. Typically, the backscatter ratio for the PSCs is larger than 1.1, and often exceeds a value of 10 in the case of ice particles (Browell et al., 1990). For the background aerosols, backscatter ratios as high as $R=1.1$ at a wavelength of $532 \mathrm{~nm}$ are observed at the altitude range from 15 to $20 \mathrm{~km}$, decreasing to $R=1$ above $30 \mathrm{~km}$, where the amount and size of aerosols have fallen below the detection limit.

Above about $30 \mathrm{~km}$, neither background aerosol, nor volcanic aerosol, nor PSCs have been found in the stratosphere by lidar. In the upper mesosphere, at altitudes of about 82 to $85 \mathrm{~km}$, the temperatures during the summer can be sufficiently low for the existence of water ice crystals. The clouds formed by these crystals are called noctilucent clouds (NLCs) or polar mesospheric clouds (PMCs) (see, e.g. Gadsden and Schröder, 1989). The atmosphere between about 30 and $80 \mathrm{~km}$ is usually free of massive aerosols $(r>10 \mathrm{~nm})$. Only in situ instruments give evidence for the existence of so-called condensation nuclei $(\mathrm{CN})$, with radii in the $10 \mathrm{~nm}$ range. Hofmann et al. (1989) and Wilson et al. (1989) found typical concentrations of about $100 \mathrm{~cm}^{-3}$ at altitudes of 20 to $25 \mathrm{~km}$ above Antarctica with concentration decreasing with height. Besides this small-sized sulphate aerosol, mineral particles of extraterrestrial origin are also found in the stratosphere. This meteoric dust remains as micrometeoroids in the stratosphere or forms from ablating meteoroids by recondensation (see, e.g. Hunten et al., 1980; Brownlee, 1985). The concentration of the meteoric dust particles varies, in general, between $10^{-4} \mathrm{~m}^{-3}$ and some $10^{9} \mathrm{~m}^{-3}$, depending on whether the particles are micrometre-sized or nanometresized, respectively.

We report on the first observation of an Arctic aerosol layer at an altitude of $38 \mathrm{~km}$ by four independent lidar stations (see Fig. 1). Following a description of the observations, the possible origin of the aerosol layer is discussed. From the results of the lidar observations, insights into polar vortex dynamics in the data-sparse altitude region above $30 \mathrm{~km}$ are derived.

\section{Instrumentation and observations}

All observations described here have been performed by lidars detecting the elastic Mie and Rayleigh backscatter of aerosols and the ambient air molecules. An Nd:YAG

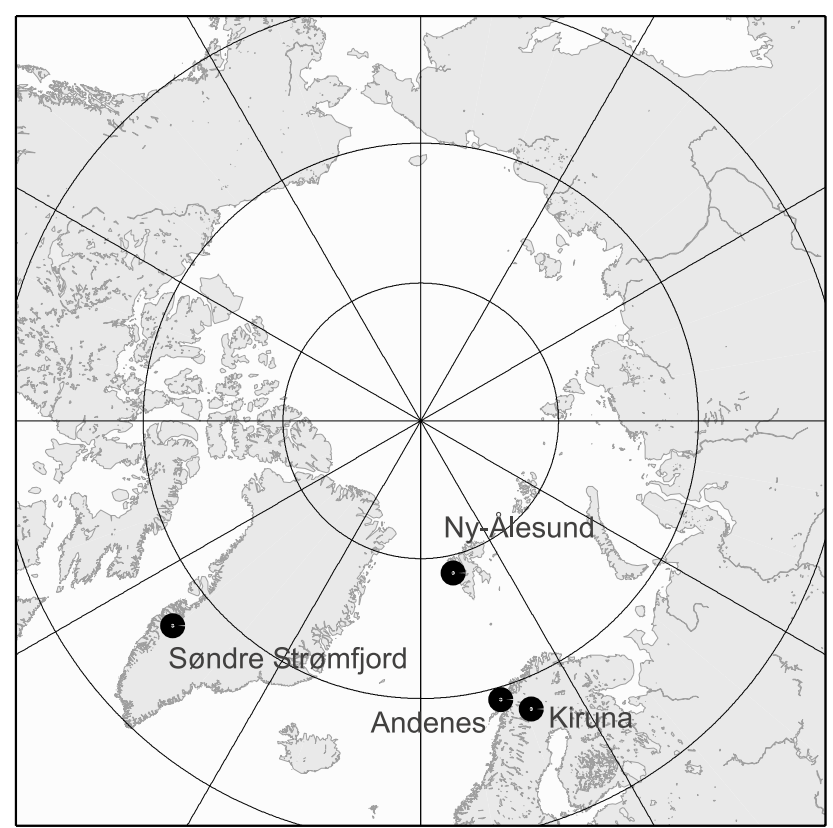

Fig. 1. Map of the Arctic region with the lidar stations contributing to the observations. Circles are at $10^{\circ}$ latitude distance.

laser was operating at each station, though at different wavelengths out of the set of fundamental, second, and third harmonics. At Ny-Ålesund (Koldewey Station lidar, $78.9^{\circ} \mathrm{N}$, $11.9^{\circ} \mathrm{E}$ ), an $\mathrm{H}_{2}$-Raman shifted $\mathrm{XeCl}$ excimer laser was also used. Table 1 provides an overview of the instrumental setup used for the observations. All systems use mechanical choppers to protect the detectors from the strong backscatter of the lower atmosphere. The molecular air density used for calculation of the backscatter ratio is obtained from MSIS E-90 model atmosphere (ARCLITE lidar, Søndre Strømfjord), a Tschebycheff polynomial fit (U. Bonn lidar at Esrange, Kiruna), $\mathrm{N}_{2}$-Raman backscatter (ALOMAR R/M/R lidar, Andenes), or NCEP analyses (Koldewey lidar, Ny-Ålesund).

On 16/17 November 2000, a small peak in backscatter ratio was observed in the Søndre Strømfjord lidar data at about $38 \mathrm{~km}$, just above the full opening of the chopper at $35 \mathrm{~km}$. The backscatter ratio $R_{532, \text { max }}$ reached a value of about 1.1 with a FWHM (full-width half-maximum) of the layer of about $2 \mathrm{~km}$ (Fig. 2). The layer had been observed to be unchanged from the beginning (21:00 UT) to the end (03:30 UT) of the measurements. The next soundings were performed seven days later on 21/22 November, but without any sign of enhanced backscatter above $30 \mathrm{~km}$. During the next operation of the lidar, on 23/24 November, the enhanced backscatter by aerosol was observed again, with only minor variations in altitude and strength. (In fact, it is not possible to distinguish between aerosol effects on backscatter ratio and incorrect assumptions on molecule density profiles. But the proof for detection of aerosols is given by the ALOMAR observations of elastic and Raman backscatter.)

Above the ALOMAR site near Andenes a mid- 
Table 1. Instrumental setup of the different lidar systems

\begin{tabular}{ccccc}
\hline lidar & ARCLITE & U. Bonn lidar at the Esrange & ALOMAR R/M/R & Koldewey \\
\hline location & Søndre Strømfjord, Greenland & Kiruna, Sweden & Andenes, Norway & Ny-Ålesund, Spitsbergen \\
latitude/longitude & $67.0^{\circ} \mathrm{N}, 50.9^{\circ} \mathrm{W}$ & $67.9^{\circ} \mathrm{N}, 21.1^{\circ} \mathrm{E}$ & $69.3^{\circ} \mathrm{N}, 16.1^{\circ} \mathrm{E}$ & $78.9^{\circ} \mathrm{N}, 11.9^{\circ} \mathrm{E}$ \\
used wavelength, nm & 532 & 532 & $1064 / 532 / 355$ & $532 / 353^{1}$ \\
output energy, mJ & 560 & 600 & $360 / 360 / 215$ & $150 / 200$ \\
repetition rate, pps & 30 & 20 & 30 & $30 / 90$ \\
telescope diameter, $\mathrm{m}$ & 0.92 & $3 \times 0.5$ & 1.8 & 0.6 \\
range resolution, $\mathrm{m}$ & 48 & 150 & 150 & 150 \\
depolarisation@ 532 nm & no & permanent & occasionally & permanent \\
reference & Thayer et al., 1997 & Müller et al., 1997 & von Zahn et al., 2000 & Beyerle et al., 2001 \\
reference density & MSISE-90 & polynomial fit & $\mathrm{N}_{2}$-Raman & NCEP \\
\hline
\end{tabular}

${ }^{1} \mathrm{H}_{2}$-Raman shifted radiation of $\mathrm{XeCl}$ excimer laser $(308 \mathrm{~nm})$

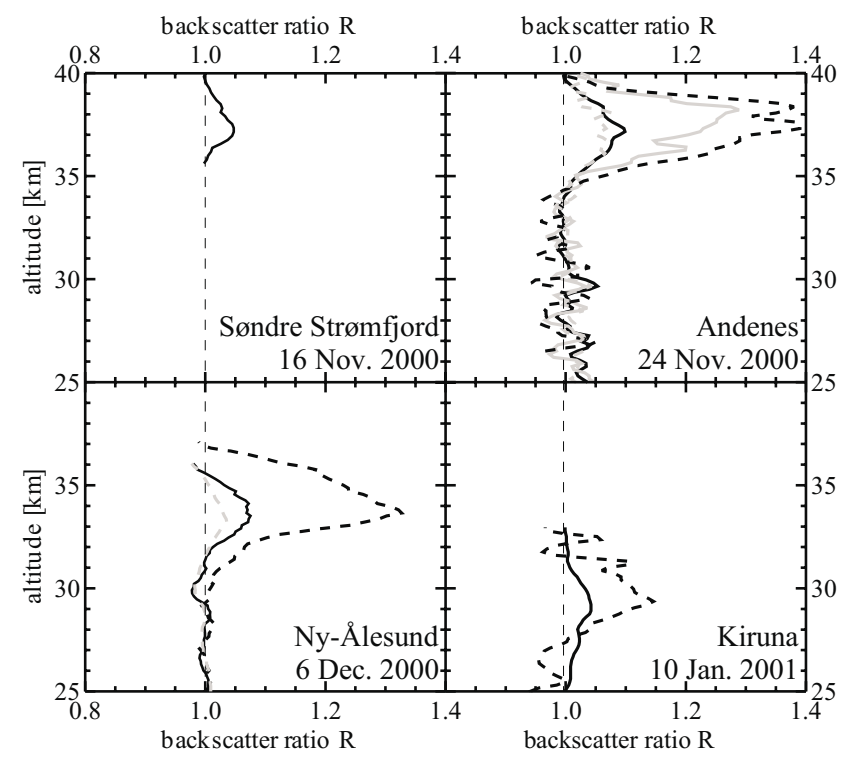

Fig. 2. Daily mean profiles of backscatter ratio for representative observations of the aerosol layer at each lidar station. Grey dashed: 355/353 nm (Andenes/Ny-Ålesund); solid black: $532 \mathrm{~nm}$ parallel polarised / non-polarised; black dashed: $532 \mathrm{~nm}$ perpendicular polarised; solid grey: $1064 \mathrm{~nm}$.

stratospheric aerosol layer with $R_{532, \max }=1.1$ was first observed on 19 November 2000. Routinely performed temperature calculations failed and led to the discovery of the aerosol layer at an altitude of about $38 \mathrm{~km}$, with a layer width of about 2 to $3 \mathrm{~km}$. Until 25 November daily soundings confirmed an aerosol layer persistently above $37 \mathrm{~km}$. The detection of the perpendicular polarised signal at $532 \mathrm{~nm}$ reveals a backscatter ratio $R_{532 x, \max }=1.4$, indicating aspherical and, thus, solid particles (Fig. 2). $250 \mathrm{~km}$ east of ALOMAR, the U. Bonn lidar at the Esrange near Kiruna started wintertime operation on 3 December 2000. During the first observation, the aerosol layer was obvious, appearing at about $36 \mathrm{~km}$ with $R_{532 p, \max }=1.06$. During the next sounding, on 5 December, the aerosol was observed around $34 \mathrm{~km}$, still with a FWHM of about $3 \mathrm{~km}$. Depolarisation measurements with the U. Bonn lidar commenced on 10 January 2001. Again, the scattering particles depolarised, must be aspherical, hence solid (Fig. 2).

From the second half of November 2000 onwards, the Koldewey lidar at Ny-Ålesund was operated routinely. A sign of enhanced stratospheric backscatter was not observed either in parallel or in perpendicular polarisation during the November observation. The first December sounding was performed on 6 December 2000. The aerosol layer was clearly visible at about $34 \mathrm{~km}$ altitude with a FWHM of about $3 \mathrm{~km}$. Figure 2 shows the higher perpendicular backscatter ratio $\left(R_{532 x, \max }=1.3\right)$ compared with backscattering of parallel polarised light $\left(R_{532}\right.$, max $\left.=1.1\right)$.

The aerosol layer was observed on several days at all sites. Table 2 lists the first and the last observation of the layer at each of the four sites. All lidars, except the one at the Esrange continued observations after the last sighting, depending on weather conditions, but no further sign of the aerosol layer was observed. Figure 3 gives an overview of the observations at a particular station and of soundings without any sign of mid-stratospheric aerosol. At Søndre Strømfjord, periods with and without aerosol layer have switched twice. At NyÅlesund the layer was not observed by the end of November, though it was detected above Scandinavia. Andenes, Søndre Strømfjord, and Ny-Ålesund failed to observe the aerosol layer between 12 and 23 December, despite there have been several hours of observations at all these stations. After this gap, which coincides with a displacement of the polar vortex due to a strong minor warming (Naujokat, 2001), the layer was always observed when the polar vortex was located above a particular lidar station (Fig. 3). At all stations, the altitude of aerosol maximum decreased almost constantly with time. Assuming that the same aerosol layer was observed at the different sites, a mean descending rate of about $145 \mathrm{~m} / \mathrm{d}$ $(0.17 \mathrm{~cm} / \mathrm{s})$ is found by linear regression.

During the descent of the aerosol layer, all stations observed only minor variations in backscatter ratio $R$ of the parallel-polarised signal (Kiruna, Ny-Ålesund) or unpolarised signal (Andenes, Søndre Strømfjord). Figure 4 pro- 
Table 2. Period of observation of the aerosol layer at different stations

\begin{tabular}{ccccc}
\hline site & $\begin{array}{c}\text { ARCLITE, } \\
\text { Søndre Strømfjord }\end{array}$ & $\begin{array}{c}\text { U. Bonn lidar } \\
\text { at the Esrange, Kiruna }\end{array}$ & $\begin{array}{c}\text { ALOMAR R/M/R, } \\
\text { Andenes }\end{array}$ & $\begin{array}{c}\text { Koldewey lidar, } \\
\text { Ny-Ålesund }\end{array}$ \\
\hline $\begin{array}{c}\text { last observation prior } \\
\text { to layer appearance } \\
\text { first observation of } \\
\text { aerosol layer } \\
\text { last observation of } \\
\text { aerosol layer }\end{array}$ & 10 November 2000 & -1 & 3 November 2000 & 27 November 2000 \\
\hline
\end{tabular}

1 no previous sounding at Esrange in winter 2000/2001

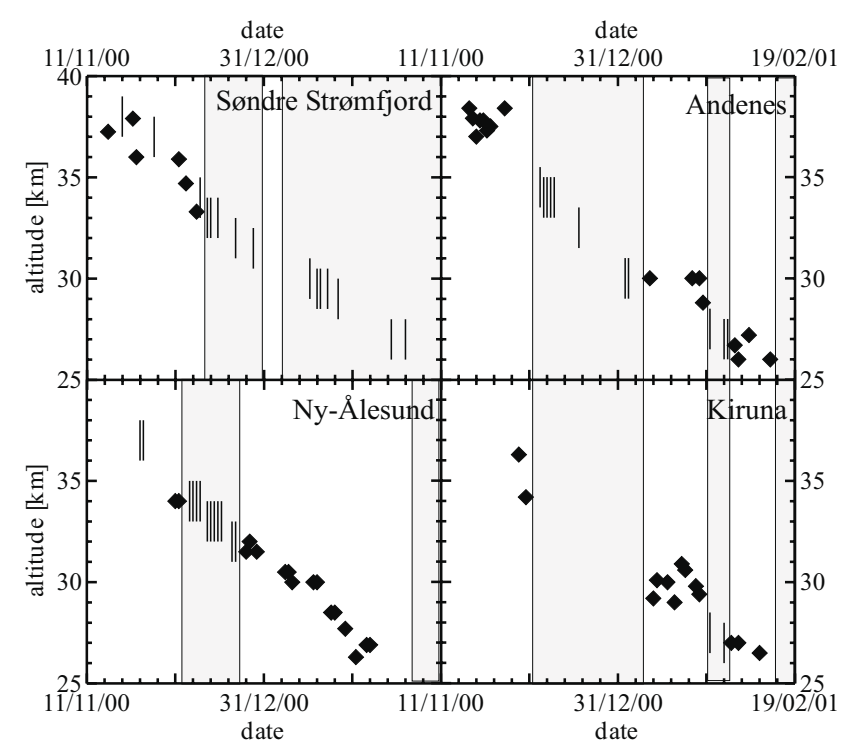

Fig. 3. Altitude of the aerosol layer during winter 2000/2001 (diamonds). Soundings without findings of the aerosol layer are marked by vertical lines. The grey shaded area marks periods where the polar vortex is not located above the lidar station. Subticks are at five-day intervals.

vides an overview of the different observations at all stations. For all particular soundings, the backscatter ratio of the depolarised signal is larger than the parallel polarised. The particles have to be non-spherical, hence, solid.

From the observed backscatter ratio, the backscatter coefficient is calculated via the equation $\beta_{\text {Aer }}=(R-1)$. $\beta_{\mathrm{Mol}}$, with $\beta_{\mathrm{Mol}}$ representing the backscatter coefficient of air molecules. Note that $\beta_{\mathrm{Mol} \text {,Aer }}$ and $R$ depend on the wavelength of light and the altitude of the sounded volume. With the accuracy of the soundings, the backscatter coefficient is about $\beta_{\text {Aer }} \approx 10^{-9} \mathrm{~m}^{-1} \mathrm{sr}^{-1}$ at $532 \mathrm{~nm}$.

\section{Discussion of the observations}

To the best of our knowledge, during winter 2000/2001, a mid-stratospheric aerosol layer was observed only by lidars distributed through the Arctic. Other instruments located in

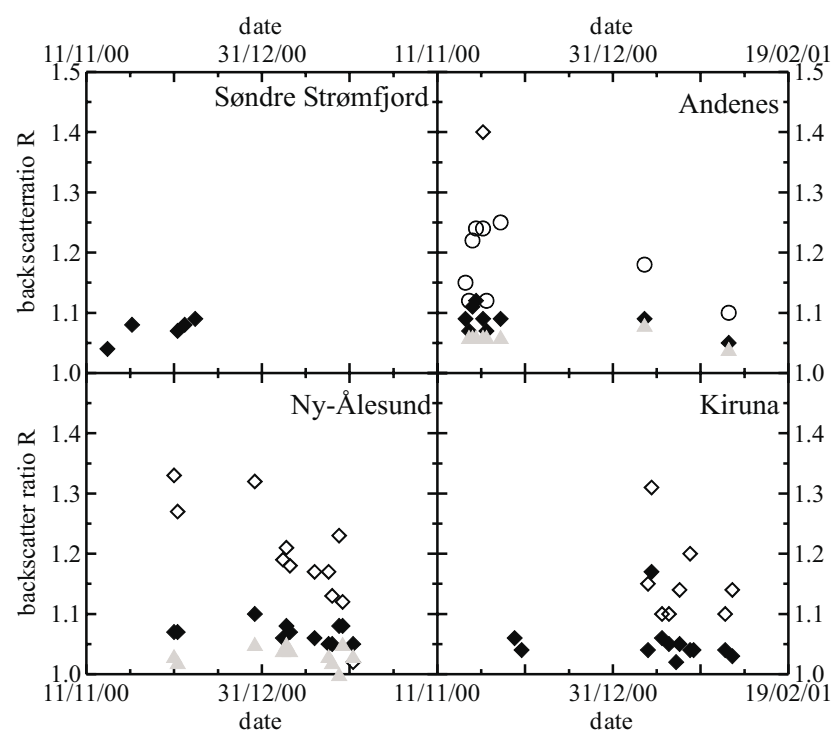

Fig. 4. Maximum backscatter ratio of the aerosol layer above the different stations, based on daily averaged data. Wavelength and polarisation are signed by marker style: $353 / 355 \mathrm{~nm}$ : grey triangles; $532 \mathrm{~nm}$ non-polarised/parallel polarised: filled diamonds; $532 \mathrm{~nm}$ perpendicular polarised: open diamonds; $1064 \mathrm{~nm}$ : open circles.

the Arctic region, including photometers and spectrometers, did not observe any signal from other than the background aerosol or polar stratospheric clouds. This includes the star photometer at Koldewey Station (Ny-Ålesund). With the observed backscatter coefficient and assuming an upper limit for the extinction to backscatter ratio of about $15 \mathrm{sr}$, the optical depth $\tau$ can be estimated to be less than $\tau(532 \mathrm{~nm}) \approx$ $10^{-5}$. This is at least two orders of magnitude below the detection limit of the photometer (Herber et al., 2002). Spaceborne spectrometers have not sounded the Arctic region (like HALOE) or do not evaluate the altitude region above $30 \mathrm{~km}$ (like SAGE II and POAM II/III) (Russell et al., 1989; Lucke et al., 1999; Randall et al., 2001a).

Since the observed enhancement in backscatter ratio is rather small, we have to carefully analyse instrumental effects leading to a "pseudo aerosol layer". The most prominent error in deriving the backscatter ratio of an aerosol layer is a density fluctuation in the atmosphere induced by a grav- 


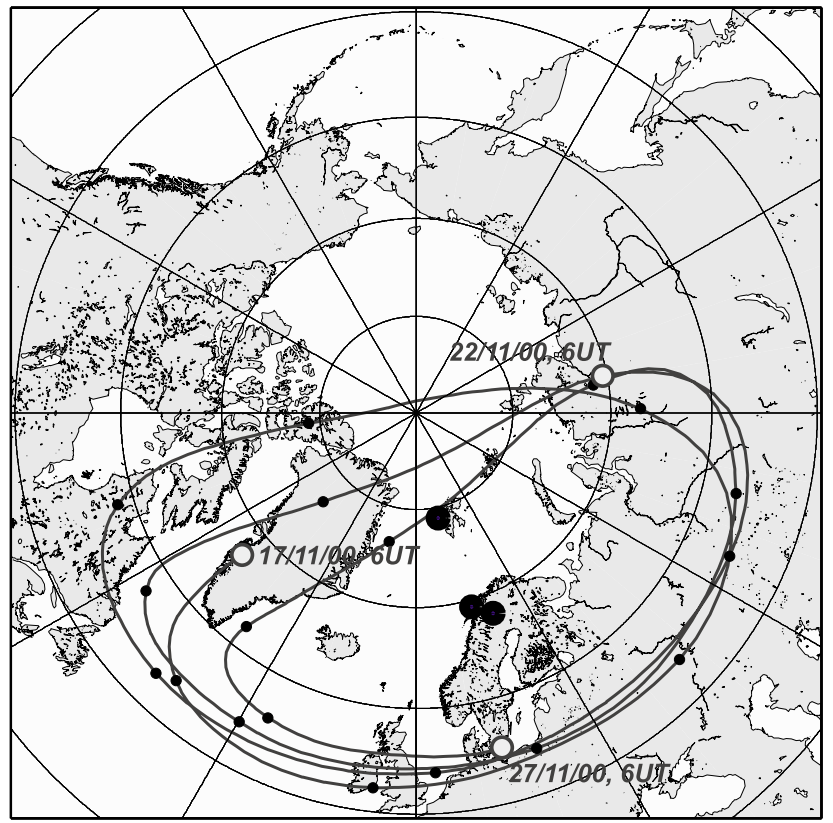

Fig. 5. Ten-day forward trajectory of the air parcel positioned above Søndre Strømfjord on 17 November 2000, 06:00 UT, at about $38 \mathrm{~km}$ altitude. The trajectory is calculated on the $1250-\mathrm{K}$-isentropic level. Markers indicate every $12 \mathrm{~h}$; circles are at $10^{\circ}$ latitude distance.

ity wave. If an atmospheric model is used to calculate the density profile of the atmosphere, the derived backscatter ratio is faulty if the model does not resolve the gravity wave. However, this problem is avoided by simultaneous observation of the molecular backscatter signal, as done by the $\mathrm{N}_{2}$ Raman channel of the ALOMAR R/M/R lidar in Andenes. Moreover, multi-wavelength observations and separated detection of parallel and perpendicular polarised light prevent the problem of misleading density profiles. Consequently, our observations present the first-time observation of massive mid-stratospheric aerosol in the Artic.

Figure 3 shows that (1) there are interruptions in the observation of the mid-stratospheric aerosol at a single location, and (2) the aerosol has been observed at a particular station and day, while there was no aerosol at one or more of the other sites. This nonuniform distribution contrasts with the similar properties of the aerosol layer measured throughout the winter and the question arises as to whether the soundings can be summarised to the observation of a single, uniform aerosol layer. Therefore, trajectories of the observed air parcels have been calculated using the wind fields of the ECMWF T-106 analyses. In Fig. 5, the path of the air parcel of the first observation of the aerosol layer is displayed for the following days, starting above Søndre Strømfjord on 17 November 2000. During the next observation with the ARCLITE lidar, on 21/22 November 2000, this air parcel was found above Siberia, several thousands of kilometres away from west Greenland. The ARCLITE lidar detected no aerosol layer on that day. An aerosol cloud of limited horizontal expansion can explain the absence of aerosol. The

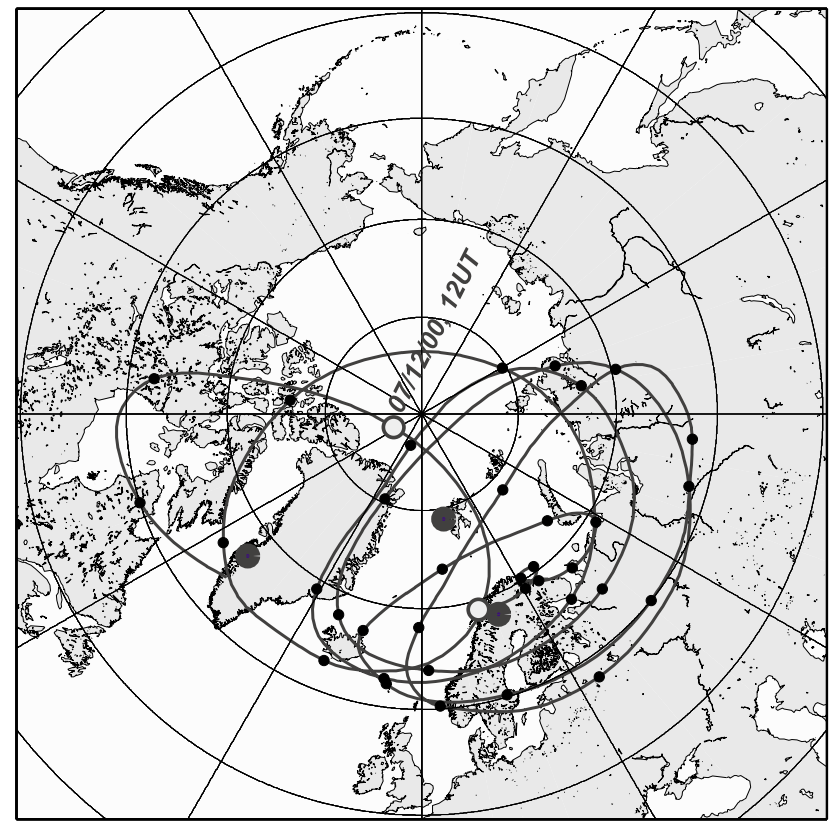

Fig. 6. Nineteen-day forward trajectory of the air parcel examined above Andenes on 20 November 2000, 00:00 UT, at about $38 \mathrm{~km}$ altitude. The trajectory is calculated on the 1250-K-isentropic level. Markers indicate every $12 \mathrm{~h}$; circles are at $10^{\circ}$ latitude distance.

observations with the ARCLITE lidar at Søndre Strømfjord during the following days can also be understood using trajectory analyses (not shown here).

Between 19 and 25 November 2000, the aerosol layer was observed on six consecutive days above Andenes, from the beginning to the end of each sounding. Trajectory calculations show that during this period the air masses circle around northern Scandinavia (Fig. 6). After about four days the same air parcel passed Andenes at only about $500 \mathrm{~km}$ distance. On 7 December, the examined air parcel passed near Spitsbergen. Therefore, the aerosol cloud observed at $\mathrm{Ny}$-Ålesund on 6/7 December is most likely the same observed at Andenes 17 days before. Neither the aerosol from Søndre Strømfjord (17 November) nor the aerosol from Andenes (20 November) came close to Ny-Ålesund during their earlier observation times. So up to the beginning of December, no more than two cloud patches are necessary to explain the observations at the four different stations, and even a single cloud patch is possible. Independent from the number of pieces, the aerosol layer has not filled the entire polar vortex.

Out of the Søndre Strømfjord observations between 7 and 13 December, 2000, only the sounding from 9 December can be explained by one of the earlier observed air parcels: the air sounded above Ny-Ålesund on 7 December is most likely the same as sounded above Greenland two days later (see Fig. 6). The other observations require the advection of previously unsounded air or the expansion of the cloud patches. After the strong minor stratospheric warming in December, with displacement of the polar vortex towards North America, the aerosol layer was observed every time at each station below 
the polar vortex (see Fig. 3). Therefore, it is reasonable to assume a further expansion of the aerosol layer during the warming period, now filling most of the vortex. This widely expanded cloud allows all observations at a particular station to be subsumed, and even all stations past mid-December. The question becomes whether or not even the first observations at Søndre Strømfjord and Andenes are compatible with the later observations of the expanded cloud: the similarity of the optical properties during the entire winter provides an explanation. Additionally, trajectory calculations directly demonstrate the coupling between observations in Andenes and $\mathrm{Ny}$-Ålesund and between observations in $\mathrm{Ny}-$ Ålesund and Søndre Strømfjord. Ultimately, the eligibility for subsuming all observations can only be given after the examination of the origin of this aerosol layer.

Surprisingly, during a short period during the following winter 2001/2002, the lidars at Kiruna, Andenes, and NyÅlesund again observed a signal from solid-phase aerosols at about $30 \mathrm{~km}$ altitude. Due to the weakness of the aerosol signal it was not possible to retrieve further aerosol properties; therefore, in the sections that follow we concentrate on the observations of the winter 2000/2001.

\section{Origin of the aerosol layer}

We begin the examination of the origin of the observed aerosol layer with a discussion as to which aerosol matter can, in principle, persist under the conditions of the middle stratosphere for a three-month winter period. Depending on material, the radii of the particles are retrieved from the lidar data. It will be demonstrated that an aerosol layer will form from vertically, broadly distributed matter of the observed properties.

\subsection{Discussion of aerosol matter}

Zhao et al. (1995) report on the model simulation of condensation nuclei $(\mathrm{CN})$ layers around $37 \mathrm{~km}$. $\mathrm{CN}$ have radii typically not greater than $10 \mathrm{~nm}$ and, thus, are smaller than the aerosol of our observations (see below). Still, $\mathrm{CN}$ are relevant because they are the biggest particles reported so far in this altitude region; further coagulation of $\mathrm{CN}$ must not be neglected directly. The studies of Zhao et al. (1995) were limited to the Antarctic spring, when mesospheric air descends into the stratosphere. This $\mathrm{CN}$ formation mechanism fails for observations in autumn and early winter. Furthermore, these $\mathrm{CN}$ are assumed to consist of sulphuric acid and, thus, to be of liquid phase. But the depolarised signal of the aerosol layer under discussion demonstrates that at least a part of the observed particles are solid. Consequently, the observed aerosol layer does not consist of CN. Additionally, the entire group of liquid aerosols, like sulphuric acid or STS, cannot be responsible for our observations.

Several types of solid aerosol can be found under different conditions in the stratosphere above $20 \mathrm{~km}$ : nitric acid trihydrate (NAT), sulphuric acid tetrahydrate (SAT), and ice

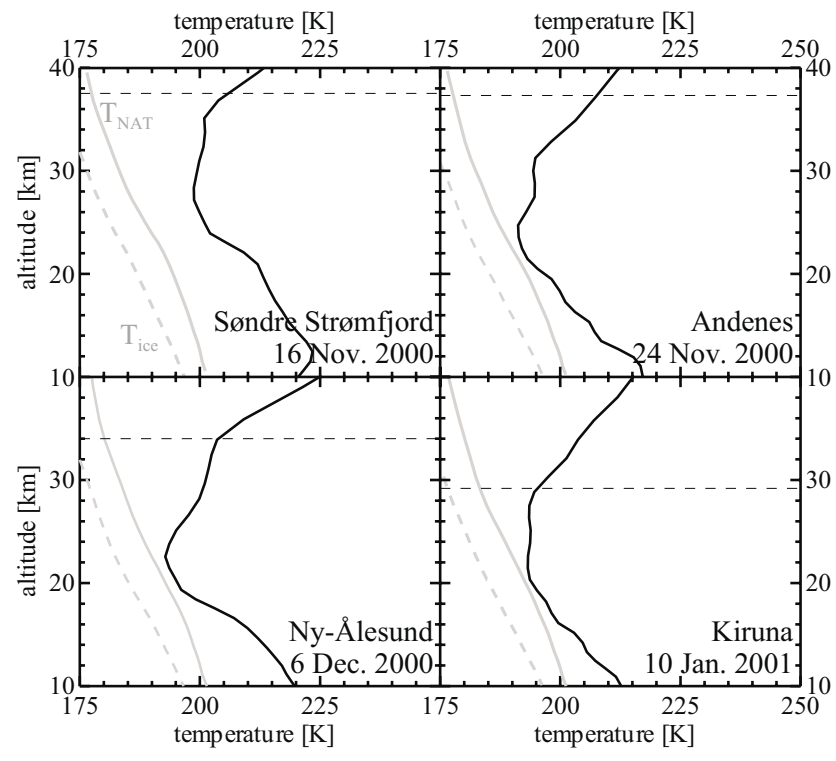

Fig. 7. Temperature profiles from ECMWF data for the observations of the aerosol layer displayed in Fig. 2. $T_{\text {ice }}$ and $T_{\mathrm{NAT}}$ (for 4.6 ppmv $\mathrm{H}_{2} \mathrm{O}$ ) are marked grey dashed and outlined, respectively. The horizontal dashed lines show the altitude of the aerosol layer.

form polar stratospheric clouds (PSCs); soot represents volcanic aerosol or kerosene exhaust; $\mathrm{Al}_{2} \mathrm{O}_{3}$ represents exhaust from solid-fueled rockets; and $\mathrm{SiO}_{2}, \mathrm{Si}, \mathrm{Na}$, and Fe represent meteoric matter coming from space. The formation of the observed aerosol layer from these types of aerosols are discussed here.

PSCs: In most cases, the observations of solid PSC particles are coupled with temperatures below the known NAT existence temperature $T_{\mathrm{NAT}}$ (Hanson and Mauersberger, 1988; Müller et al., 2001). Only few solid PSCs particles have been detected at higher ambient temperatures, interpreted as SAT (Beyerle et al., 2001). Figure 7 gives the temperature profiles from ECMWF data for the observations displayed in Fig. 2. At all stations, the temperatures are several ten Kelvin higher than $T_{\mathrm{NAT}}$. During the preceding days, variations of up to $15 \mathrm{~K}$ were found in the examined air parcels (not shown here), but at all times the ambient temperature was well above $T_{\mathrm{NAT}}$. For the formation of NAT on preexisting ice particles, even lower temperatures $T_{i c e}$ are necessary (Peter et al., 1994; Koop et al., 1997). The possibility of strongly misleading ECMWF analyses during the entire 2.5month period of cloud observation can be neglected. Furthermore, the regular temperature soundings with the ALOMAR R/M/R lidar show the ECMWF analyses to be reasonable (above the layer).

While the air temperature is too high to allow NAT existence under typical atmospheric conditions, it is important to address disturbances that lead to an increase in the existence temperature $T_{\mathrm{NAT}}$. Typically, an increase in water vapour concentration $\left[\mathrm{H}_{2} \mathrm{O}\right]$ of $1 \mathrm{ppmv}$ would raise $T_{\mathrm{NAT}}$ by about $0.8 \mathrm{~K}$, while an approximate doubling of $\left[\mathrm{HNO}_{3}\right]$ is needed for the same effect. Figure 8 shows the result of in- 


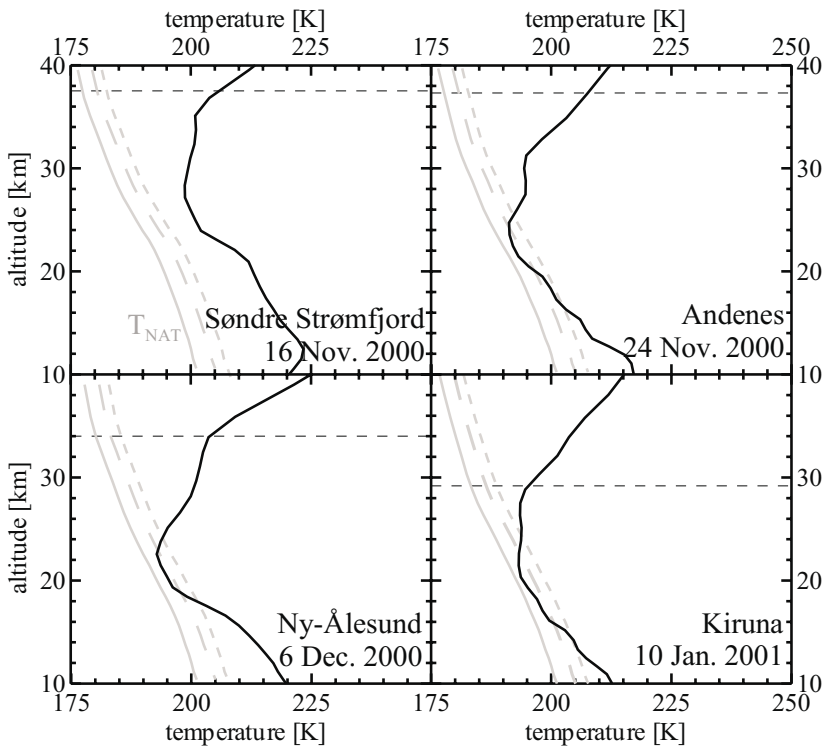

Fig. 8. Temperature profiles from ECMWF data for the observation of the aerosol layer displayed in Fig. 2. $T_{\mathrm{NAT}}$ is shown for comparison for typical $\mathrm{H}_{2} \mathrm{O}$ and $\mathrm{HNO}_{3}$ concentrations and increased concentrations (long dashed: $\left[\mathrm{H}_{2} \mathrm{O}\right]+3 \mathrm{ppmv},\left[\mathrm{HNO}_{3}\right] \cdot 3$; short dashed: $\left[\mathrm{H}_{2} \mathrm{O}\right]+6$ ppmv, $\left.\left[\mathrm{HNO}_{3}\right] \cdot 6\right)$. The horizontal dashed lines show the altitude of the aerosol layer.

creasing $T_{\mathrm{NAT}}$ due to increasing $\left[\mathrm{H}_{2} \mathrm{O}\right]$ and $\left[\mathrm{HNO}_{3}\right]$. An increase in $\left[\mathrm{NO}_{2}\right]$ by a factor of 2 to 3 , which is also coupled with an increase in $\left[\mathrm{HNO}_{3}\right]$, was, for example, observed by POAM III in the Southern Hemisphere polar vortex after a strong Solar Proton Event (SPE) in July 2000 (Randall et al., 2001b). SPE can also influence the concentrations of $\mathrm{HO}_{\mathrm{y}}$ (e.g. $\mathrm{OH}, \mathrm{HO}_{2}$ ) in the upper stratosphere and mesosphere (Jackman et al., 2000, 2001; Randall et al., 2001b) and are suggested to induce the formation of $\mathrm{CN}$ in the midstratosphere (Hofmann and Rosen, 1983). Several days before the first observation of the mysterious aerosol layer, during 8-10 November 2000, another strong SPE occurred. It provided a proton flux of about one-third compared with July 2000 (15000 protons $\mathrm{cm}^{-2} \mathrm{~s}^{-1} \mathrm{sr}^{-1}$ and 50000 protons $\mathrm{cm}^{-2} \mathrm{~s}^{-1} \mathrm{sr}^{-1}$, respectively) (public data of GOES instruments available via Space Physics Interactive Data Resource SPIDR, http://spidr.ngdc.noaa.gov/spidr/). Though this SPE may have influenced some trace gas concentrations, the possibility of a subsequent increase in $T_{\mathrm{NAT}}$ by several $10 \mathrm{~K}$ can be neglected. Therefore, a relation between the observed aerosol layer and the solar proton event has to be ruled out, as well as any NAT aerosol, in general.

Within publications of polar stratospheric cloud observations there is a discussion concerning the existence of solid cloud particles above the NAT existence temperature (see, for example, Beyerle et al., 2001). Sulphuric acid tetrahydrate (SAT) will freeze under small supersaturation heterogeneously on preexisting aerosols at temperatures near the freezing temperatures of ice (Larsen et al., 1995). After formation, the SAT particles are metastable and will melt again at temperatures about $15 \mathrm{~K}$ above their freezing temperature. But during the observations of the aerosol layer, the ambient temperatures are still not low enough for SAT freezing or existence (Fig. 7).

Soot $/ \mathrm{Al}_{2} \mathrm{O}_{3}$ : Volcanoes or kerosene-fueled airplanes and rockets can produce soot in the stratosphere. Pinto et al. (1989) suggest volcanic soot particles larger than $1 \mathrm{~mm}$, but those reside for only a few weeks within the atmosphere. But there is also evidence for the formation of smaller soot particles (see, for example, Sheridan et al., 1994). However, no volcanic eruption is reported in 1999/2000 that is strong enough to inject matter into the stratosphere. Newman et al. (2001) report the observation of soot and sulphate aerosol at about $20 \mathrm{~km}$ altitude on 18 April 1997, that was traced back to a Russian Soyuz launch from Baykonur (Kazakhstan) 12 days before. For autumn 2000, several rocket launches from mid and high northern latitudes are listed in Jonathan McDowell's Space Report No. 444 (http://hea-www.harvard.edu/ jcm/space/jsr/jsr.html). The only reported launch of a kerosene-fueled rocket was from Baykonur $\left(45.6^{\circ} \mathrm{N}, 63.4^{\circ} \mathrm{E}\right)$ on 1 November 2000 . Unfortunately, direction and apogee of this suborbital launch is not available to the public. But we estimate that this military intercontinental ballistic missile could have injected matter in the correct location, since it is able to reach, for example, the Barents-Sea region from the launch site. In addition to the kerosene-fueled rockets, solid-fueled rockets are being launched, which, among other things, exhaust solid aluminium oxides like $\mathrm{Al}_{2} \mathrm{O}_{3}$ (Jones et al., 1995). On 12 September 2000, a Russian solid-fueled rocket was launched from a submarine in the Barents Sea. Additionally, on 26/27 September and 11 October solid-fueled rockets were launched from mobile terrestrial platforms somewhere in Russia. It is possible that additional launches for military purposes have been made, but this information cannot be confirmed. It is likely that all launches will result in some thousands of kilograms of exhaust being injected into the atmosphere. This material will be broadly distributed along the path of the rocket. Further mechanisms leading to a stratification of the aerosols are needed and will be discussed later.

Meteoroids: Finally, we discuss the entry of meteoric matter into the stratosphere. In general, meteoric matter can undergo different processes within the atmosphere: (1) Micrometeoroids of up to $100 \mu \mathrm{m}$ radius pervade the atmosphere unmelted (see, for example, Brownlee, 1985). (2) Centimetre-sized and larger meteoroids can form so-called meteor smoke particles (MSP) of some nanometres size by ablation and recondensation within a few minutes (Rosinski and Snow, 1961; Hunten et al., 1980). Within the trail of larger meteoroids the MSP density is high enough for further coagulation of the particles. (3) Part of a larger meteoroid may not vaporise, but rather split into small particles due to mechanical stress and atmospheric drag forces. The micrometeoroids - or "Brownlee particles" - sediment into the stratosphere, where they form part of the background aerosol. Meteor showers may produce layers of increased particle density (Mateshvili et al., 1999), but no me- 
Table 3. Particle radii and aspect ratios matching the observations at ALOMAR on 22 and 24 November 2000. Mode-width is $\sigma=1.4$

\begin{tabular}{ccccccc}
\hline & soot & $\mathrm{Al}_{2} \mathrm{O}_{3}$ & $\mathrm{SiO}_{2}$ & $\mathrm{Fe}$ & $\mathrm{Na}$ & $\mathrm{Si}$ \\
\hline $\begin{array}{c}\text { radius from colour } \\
\text { ratio, nm } \\
\text { aspect ratio }\end{array}$ & $30-40$ & $40-50$ & $40-50$ & $30-35$ & - & - \\
\hline
\end{tabular}

teor shower was observed during the period of interest. The Leonid meteor shower occurred shortly after the first observations (Arlt and Guyssens, 2000). Larger meteoroids, heavier than $1000 \mathrm{~kg}$, enter the Earth's atmosphere in numbers of 1000 per year (Ceplecha et al., 1998). Many of the larger meteoroids remain unobserved, because they occur above oceans or sparsely populated regions. Reentering satellites undergo, in principle, processes similar to those of an ablating meteoroid. But to the best of our knowledge, no satellite reentry has been documented during autumn 2000. Therefore, various stratospheric aerosols, rocket exhaust, as well as matter from large meteoroids, continue to be possible sources of the observed aerosol layer.

\subsection{Size calculations from observed parameters}

Lidar observations of the aerosol layer at different wavelengths and the analysis of the polarisation of the backscattered light are used to retrieve further information concerning particle shape and size of the aerosol. As described in Table 1, the ALOMAR R/M/R (Andenes) data set is the most extensive with respect to the wavelengths used. Lidar soundings have been performed at three different wavelengths $(1064 \mathrm{~nm}, 532 \mathrm{~nm}$, and $355 \mathrm{~nm})$, with optional detection of the perpendicular polarised signal at $532 \mathrm{~nm}$. At Koldewey Station (Ny-Ålesund), the two emitted wavelengths of $532 \mathrm{~nm}$ and $353 \mathrm{~nm}$ were used, including perpendicular polarisation at $532 \mathrm{~nm}$. The U. Bonn lidar at the Esrange (Kiruna) determined the polarisation of the backscattered light at $532 \mathrm{~nm}$.

Two- and three-colour observations allow for the calculation of colour ratios defined as the quotient of backscatter coefficients at different wavelengths, $\left(\beta\left(\lambda_{1}\right) / \beta\left(\lambda_{2}\right)\right)$. To derive the size of the aerosol particles, we have compared the observed colour ratios with those of a log-normal distributed ensemble of randomly oriented particles calculated by the Tmatrix method (Mishchenko, 1991). These calculations were performed for different types of materials, defined by their refractive index used for the T-matrix calculations. Six materials are considered: soot (volcanic ash, kerosene exhaust) $\mathrm{Al}_{2} \mathrm{O}_{3}$ (exhaust from solid-fueled rockets); and $\mathrm{SiO}_{2}, \mathrm{Si}, \mathrm{Na}$, and $\mathrm{Fe}$ (meteoric matter).

As previously described, the observed backscatter ratios, and, therefore, colour ratios (CR), have been about constant during the entire sounding period. So the mean profiles of 22 November 2000 from ALOMAR R/M/R lidar have been used to derive the particle sizes because of very good signal- to-noise ratio. The CRs are nearly constant with altitude throughout the layer, giving $C R(355 / 532)=(1.5-2.8)$ and $C R(1064 / 532)=(0.10-0.13)$. This CRs are reproduced by a log-normal distribution with a distribution width of $\sigma=1.4$, but not by a monodisperse $(\sigma=1.0)$ ensemble of particles. The range of observed CRs results in a $25 \%$ variation of the infered radii. For soot, oxides, and iron, the particle radii vary between 30 and $50 \mathrm{~nm}$, but sodium and silicon do not generate the observed colour ratios at all.

The depolarisation measurement at Andenes on 24 November 2000, shows an aerosol depolarisation of $\delta_{a}=$ $(2.2 \pm 0.2) \%$. The depolarisation was compared with those of ellipsoids with different aspect ratios (length-to-diameterratio), but a volume equivalent radius as derived from the CRs. Table 3 summarises particle radii and aspect ratios for ellipsoids with depolarisation ratios of $\delta_{a}=2.2 \%$.

The data from 22 and 24 November 2000 are representative of the observations at ALOMAR (Andenes). Later observations from Koldewey lidar in Ny-Ålesund, as well as depolarisation measurements from U. Bonn lidar in Kiruna, reproduce the ALOMAR results well within the given error limits. Hence, we conclude that the aerosol layer may consist of soot, $\mathrm{Al}_{2} \mathrm{O}_{3}, \mathrm{SiO}_{2}$, or iron particles with radii of about 30 to $50 \mathrm{~nm}$.

A crude estimation of the total aerosol mass can be given by using the trajectory calculations from Figs. 5 and 6. From the observed backscatter coefficient $\beta_{532, \text { Aer }} \approx$ $10^{-9} \mathrm{~m}^{-1} \mathrm{sr}^{-1}$ and a typical backscatter cross section of $\sigma_{532, \text { Aer }} \approx 10^{-14} \mathrm{~m}^{2} \mathrm{sr}^{-1}$, a particle density of about $N \approx$ $10^{5} \mathrm{~m}^{-3}$ can be estimated via $N=\beta_{\text {Aer }} / \sigma_{\text {Aer }}$. This particle density results in a mass density of about $10^{-13} \mathrm{~kg} \mathrm{~m}^{-3}$, using the properties described above. From the continuous observation between 19 and 26 November 2000, above Andenes, and the trajectories of the examined air parcels, we can estimate the size of this cloud patch to be about $1000 \times 500 \mathrm{~km}^{2}$. Assuming as a first guess the same for the patch being responsible for the Søndre Strømfjord observations, we find a lower limit of the total mass of about $200 \mathrm{~kg}$. Due to various error sources (like particle density and expansion of the layer) the lower limit of the mass may be up to $2000 \mathrm{~kg}$.

\subsection{Sedimentation and layer formation}

Rocket exhaust is most likely distributed over large parts of the stratosphere and mesosphere, but a meteoroid may distribute the aerosol only in a height interval of some few kilometres, depending on the flight path. The direct formation of a maximal $3 \mathrm{~km}$ thick, but several hundreds of kilometres wide, aerosol layer by a shallow invading meteoroid, while unlikely, should not be ignored. Therefore, the possibility of forming an aerosol layer by sedimentation is discussed.

The descent of particles of given size and mass, initially distributed between 50 and $70 \mathrm{~km}$, has been simulated. The terminal velocity of a particle has been calculated at 78 altitude levels, with the levels nearly logarithmically distributed on a pressure scale between 0.01 and $30 \mathrm{hPa}$ (about 80 and 


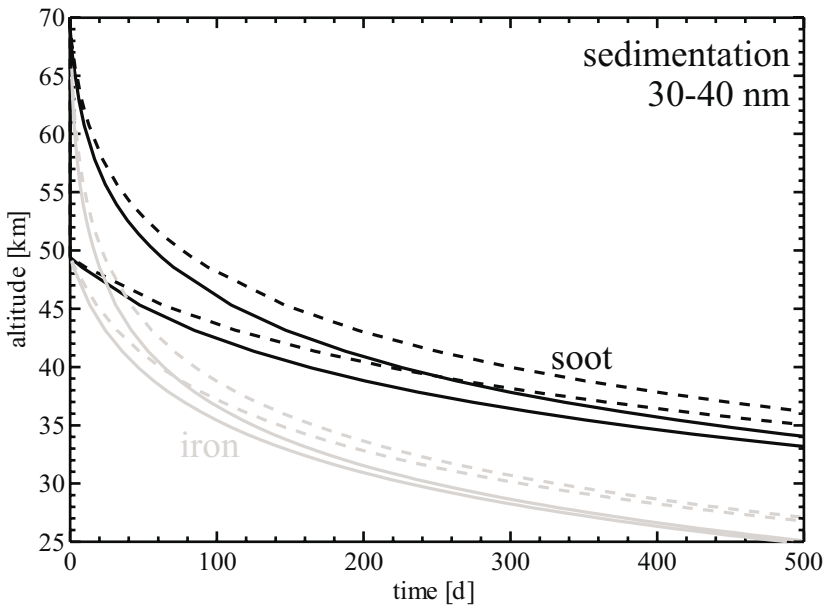

Fig. 9. Sedimentation of soot $\left(\rho=2240 \mathrm{~kg} / \mathrm{m}^{3}\right)$ and iron $(\rho=$ $7900 \mathrm{~kg} / \mathrm{m}^{3}$ ) particles with 30 and $40 \mathrm{~nm}$ radius (dashed line and solid line, respectively). Initial altitudes at $t=0$ are 50 and $70 \mathrm{~km}$.

$24 \mathrm{~km}$, respectively). The terminal velocity has been derived according to the equations given by Pruppacher and Klett (1997). In the upper stratosphere and mesosphere the mean free path of the air molecules is much larger than the diameter of the aerosol particles. Therefore, the so-called Cunningham slip-flow has to be taken into account (Pruppacher and Klett, 1997). The fields of pressure, temperature, and altitude have been used from the zonally averaged COSPAR International Reference Atmosphere 1986 (CIRA-86) for November and $65^{\circ}$ latitude (Fleming et al., 1990). The sedimentation time has been derived from the mean velocity between two levels.

Figure 9 gives an example of the sedimentation of soot and iron particles, representing the slowest and the fastest particles discussed here. A size separation that occurs during the descent is apparent. This size separation limits the vertical thinning of the layer and causes a layer thickness of from 2 to $4 \mathrm{~km}$ below $40 \mathrm{~km}$ for both types of aerosols. Because the initial sedimentation of particles from higher than $70 \mathrm{~km}$ is very fast, the particles do not have to be considered separately, but are well represented by the $70 \mathrm{~km}$ particles. A mean sedimentation velocity can be calculated from the descending particle ensemble: Between 35 and $30 \mathrm{~km}$ layer altitude it amounts to about $10 \mathrm{~m} / \mathrm{d}(0.01 \mathrm{~cm} / \mathrm{s})$ and $34 \mathrm{~m} / \mathrm{d}$ $(0.04 \mathrm{~cm} / \mathrm{s})$ for soot and iron, respectively.

\section{Discussion of aerosol source}

The described sedimentation rate of 10 to $34 \mathrm{~m} / \mathrm{d}$ is much less than the value of $145 \mathrm{~m} / \mathrm{d}(0.17 \mathrm{~cm} / \mathrm{s})$, which has been observed as an average of all observations at the four lidar sites. By sedimentation only, it would take more than 80 days in the case of iron particles (or more than 300 days for soot) to form a layer and to descend from the mesosphere down to about $37 \mathrm{~km}$. During the entire period, the aerosol-laden air would be mixed with "clean" air and the aerosol would be di- luted during the sedimentation. Therefore, both the layering of the aerosol, as well as the further descent of the layer during its observation cannot be explained solely by sedimentation. Additional mechanisms, like the diabatic descending of the air within the polar vortex, are needed to explain the observed sedimentation. Rocket exhaust has been observed occasionally by lidar some minutes after emission in the upper mesosphere (Fricke et al., 1995) or some days after emission in the lower stratosphere (Newman et al., 2001). But for the continuous observation of the aerosol layer described here, the rocket or meteoroid event has to take place within the self-contained air mass of the polar vortex, to decelerate or even inhibit the dilution of the aerosol, as an additional precondition. Therefore, from the comparatively large number of rocket launches and large meteoroid entries, only a small fraction would produce an aerosol layer of the observed type.

In the preceding sections it was assumed that the same widely expanded aerosol layer was sounded at the different stations after the middle of December. Nonetheless, the initial observations at Søndre Strømfjord (Greenland) and Andenes (Norway), together with the analysis of the trajectories show that initially the layer separated into two parts or was elongated from the centre to the edge of the vortex. But up to now it remained an open question as to how such a single event could produce two different aerosol patches or a single cloud several thousand kilometre in length. (1) Two rockets or two meteoroids have produced the aerosol independently. Yet it seems unlikely that two events originate aerosol independently in an altitude where it has never been observed before by lidar. (2) A single rocket flight or a single probably broken meteoroid has produced the aerosol layer, which has been separated/elongated later by wind shear.

To prove the second scenario, backward trajectories have been calculated based on ECMWF T-106 analyses. For the calculations, the isentropic level of $1250 \mathrm{~K}$ (about $37 \mathrm{~km}$ ) has been chosen and sedimentation has been neglected. Two air parcels have been traced, starting at Søndre Strømfjord on 16 November 2001, and at Andenes on 19 November 2001, representing the first observations of the aerosol layer at these sites. In addition, the position of the parcels and their distance has also been calculated. During some days around 3 November 2001, the distance was found to be only about $600 \mathrm{~km}$. While the accuracy of the trajectories after two weeks of calculation is limited, it seems at least likely that the sounded air parcels have had the same origin in a region of less than $1000 \mathrm{~km}$ diameter. The initial event for the formation of the aerosol layer may have happened earlier, but at least up to the beginning of November the aerosol layer was of limited extent. By the beginning of November, the traced air parcels were located in the Barents Sea between Spitsbergen, Novaya Zemlya (Russia) and the Scandinavian Peninsula. 


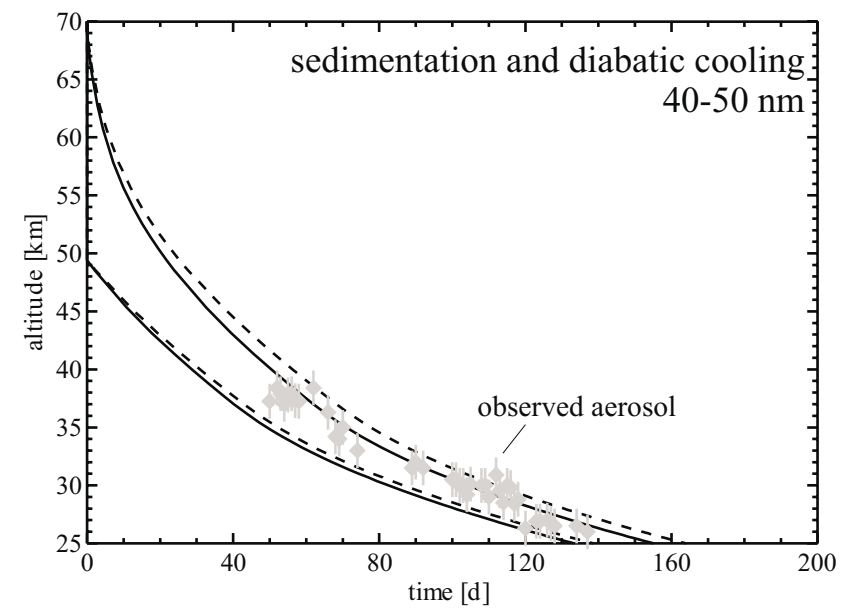

Fig. 10. Descent of 40 to $50 \mathrm{~nm}$ particles (dashed line and solid line, respectively) with typical density of meteoric matter or $\mathrm{Al}_{2} \mathrm{O}_{3}$ $\left(\rho=3500 \mathrm{~kg} / \mathrm{m}^{3}\right)$. Additional diabatic sinking is forced; see text for further details. The markers symbolize the observed aerosol layer maximum with 16 November 2000 set to day 50. The vertical lines indicate the average FWHM of the layer.

\section{Diabatic sinking within the polar vortex}

From the calculated sedimentation of aerosol in the stratosphere and the observed altitudes of the aerosol layer during winter 2000/2001, conclusions for the descent of the air due to diabiatic cooling within the polar vortex can be derived. As previously stated, the sedimentation of the aerosol is much slower than the observed descending velocity of the aerosol layer ( 10 to $34 \mathrm{~m} / \mathrm{d}$ vs. $145 \mathrm{~m} / \mathrm{d}$ ). To account for this difference, the descending velocity of an air parcel due to diabatic cooling has been added to the sedimentation scheme. A profile of residual vertical velocity from diabatic cooling is taken from Schoeberl et al. (1992) for $70^{\circ} \mathrm{N}$, with an additional height-independent scaling factor estimated as a best fit for the observations. Schoeberl et al. (1992) present latitude-dependent zonal mean vertical velocities up to $37 \mathrm{~km}$ altitude. The data are derived from model analyses during an aircraft campaign between 3 January and 10 February 1989. Results of our calculations are shown in Fig. 10. Since we cannot distinguish between the above-mentioned materials, we choose a particle density of $\rho=3500 \mathrm{~kg} / \mathrm{m}^{3}$ and radii between 40 and $50 \mathrm{~nm}$. The density is representative for typical meteoric dust, as well as $\mathrm{Al}_{2} \mathrm{O}_{3}$. The values of soot or iron aerosol (30 to $40 \mathrm{~nm}$ radius, $\rho=2240 \mathrm{~kg} / \mathrm{m}^{3}$ or $\rho=7900 \mathrm{~kg} / \mathrm{m}^{3}$, respectively) are used as upper and lower limits. The best match between observed and calculated descending velocities in the 30 to $35 \mathrm{~km}$ range was obtained with a scaling factor of about 0.75 compared with the profile from Schoeberl et al. (1992).

Table 4 shows the derived vertical velocities from diabatic cooling at various altitude levels. By combining sedimentation and diabatic sinking of the polar vortex air, a thin aerosol layer will be formed much faster than by sedimentation only (compare Fig. 9). Still, the calculated layer width around day
Table 4. Descending velocity of an aerosol layer in the middle stratosphere. Downward velocities are defined to be positive. Numbers are for $\rho=3500 \mathrm{~kg} / \mathrm{m}^{3}$ with results for soot and iron given in brackets ( $\rho=2240 \mathrm{~kg} / \mathrm{m}^{3}$ and $\rho=7900 \mathrm{~kg} / \mathrm{m}^{3}$, respectively). The sinking rate due to diabiatic cooling $w_{\text {cool }}$ is scaled by $0.75(0.6$ to 0.75 ) with respect to the data of Schoeberl et al. (1992)

\begin{tabular}{ccccc}
\hline altitude $[\mathrm{km}]$ & $w_{\text {total }}[\mathrm{m} / \mathrm{d}]$ & $w_{\text {sedi }}[\mathrm{m} / \mathrm{d}]$ & $w_{\text {cool }}[\mathrm{m} / \mathrm{d}]$ & $w_{\text {cool,edge }}[\mathrm{m} / \mathrm{d}]$ \\
\hline 35 & 191 & 29 & 162 & \\
& & $(15-51)$ & $(140-176)$ & \\
30 & 121 & 14 & 107 & $155^{1}$ \\
$35-30$ & 144 & $(7-25)$ & $(96-114)$ & $(145-163)$ \\
& & $(10-34)$ & $(110-134)$ & \\
\hline
\end{tabular}

${ }^{1}$ derived from the observed descent after 14 January 2000, and the calculated sedimentation velocity $w_{\text {sedi }}$

50 is about twice as large as observed, due to the assumed diabatic-sinking rate above $37 \mathrm{~km}$. Since there is a lack of serious data for the upper stratosphere, we have conservatively assumed that the sinking velocity above $37 \mathrm{~km}$ will not further increase. A more realistic increase in velocity would result in a layer of less vertical width.

From mid-January 2001 until the end of the aerosol observation one month later, Kiruna and Andenes were at the edge of the polar vortex or outside. All detections of the aerosol layer have been performed, when the station was below the edge of the vortex, but not clearly outside. A linear regression from the altitudes of the layer limited to this period reveals a descending velocity of about $170 \mathrm{~m} / \mathrm{d}$, hence, somewhat higher than the winter mean of all observations (see Fig. 3). The observed descent of the aerosol requires a vertical velocity due to diabatic cooling of about $155 \mathrm{~m} / \mathrm{d}(0.18 \mathrm{~cm} / \mathrm{s})$, with limits caused by the aerosol matter of $145 \mathrm{~m} / \mathrm{d}(0.17 \mathrm{~cm} / \mathrm{s})$ and $163 \mathrm{~m} / \mathrm{d}(0.19 \mathrm{~cm} / \mathrm{s})(\mathrm{see}$ Table 4). This is very close to the value published by Schoeberl et al. (1992).

\section{Summary and conclusions}

Between 16 November 2000 and 12 February 2001, a unique aerosol layer was observed by lidar instruments at four different Arctic stations. The soundings were performed independently at Søndre Strømfjord, Greenland (ARCLITE lidar, $67.0^{\circ} \mathrm{N}, 50.9^{\circ} \mathrm{W}$ ); Kiruna, Sweden (U. Bonn lidar at the Esrange, $67.9^{\circ} \mathrm{N}, 21.1^{\circ} \mathrm{E}$ ); Andenes, Norway (ALOMAR $\mathrm{R} / \mathrm{M} / \mathrm{R}$ lidar, $69.3^{\circ} \mathrm{N}, 16.1^{\circ} \mathrm{E}$ ); and Ny-Ålesund, Spitsbergen (Koldewey Station lidar, $78.9^{\circ} \mathrm{N}, 11.9^{\circ} \mathrm{E}$ ). During the three-month period, the aerosol layer descended from about 38 to $26 \mathrm{~km}$. Up to the beginning of December, only a portion of the polar vortex was filled by one or more aerosol cloud patches. After mid-December 2000, the entire polar vortex has been filled with the aerosol in a distinct layer of about $3 \mathrm{~km}$ thickness. 
We have derived phase and size of the aerosols from the lidar soundings of the aerosol layer. These observations show that the particles were solid. Because of the ambient temperatures and trace gas concentrations, typical solid stratospheric aerosols, like nitric acid trihydrate and ice, are ruled out. Therefore, injected "artificial" aerosols, like rocket exhaust or meteoric dust, have been discussed. Three-colour observations and depolarisation measurements show that the aerosol layer may have consisted of soot, $\mathrm{Al}_{2} \mathrm{O}_{3}, \mathrm{SiO}_{2}$, or iron particles. The particle size has been found to be between 30 and $50 \mathrm{~nm}$ with a particle density of about $10^{5} \mathrm{~m}^{-3}$. The total mass of the aerosol layer has been roughly estimated to be 200 to $2000 \mathrm{~kg}$, hence, in the mass range of large meteoroids or the fuel weight of intercontinental/suborbital rockets.

Direct proof cannot be given for either scenario, but the entry of a larger meteoroid within the polar region, as well as the launch of a ballistic rocket from Russia, are possible or have been confirmed. For both schemes the circulation of the aerosol cloud within the polar vortex and the low mixing across the border of the vortex is essential for a layer formation and succeeding observation by lidar. During the formation of the layer, the aerosol-laden air masses remained unchanged - the layer had not been diluted by "clean" air during the nearly three months of observation. This dilution would have reduced the backscatter coefficient significantly and would soon have inhibited the detection by lidar. Outside the polar vortex, eddy-mixing may be the main reason that mid-stratospheric layered aerosol has not been observed previously by lidar. Rocket launches or meteoroid impacts occur frequent enough to "pollute" the atmosphere occasionally. By chance they may occur inside the polar vortex and an aerosol layer can be formed from the released particles.

The observation of this unique mid-stratospheric aerosol layer coincides with other unique events in the north polar winter 2000/2001: Manney et al. (2001a, b) report on a unique stratospheric warming starting by mid-November 2000 in the lower and middle stratosphere, therefore, below the aerosol layer described here. Kivi et al. (2001) have observed vertically thick PSCs in January 2001 above Sodankylä $\left(67^{\circ} \mathrm{N}, 27^{\circ} \mathrm{E}\right)$, which they ascribe to the ambient low temperatures. Their in situ observations are limited to the region below the aerosol layer, where the lidar has not detected any aerosol previous to the PSCs. Therefore, a connection can be ignored. Various researchers have published their results on heterogeneous chemical reactions on rocket exhaust particles (e.g. Jones et al., 1995; Jackman et al., 1998). But the impact of the described aerosol layer, for example, on the ozone concentration, should be small, because transport processes dominate the ozone distribution against chemical reactions at these high altitudes (Solomon et al., 1996).

The comparison of the observed layer descent with the calculated sedimentation velocity of the aerosol allows to estimate the mean vertical velocity due to the diabatic cooling within the polar vortex. The altitude gradient of vertical velocity was taken from Schoeberl et al. (1992). Best agree- ment with our observation was achieved by scaling the published profile by 0.75 . We obtain mean vertical velocities due to diabatic cooling of $162 \mathrm{~m} / \mathrm{d}$ (140 to $176 \mathrm{~m} / \mathrm{d}$ ) at $35 \mathrm{~km}$ and $107 \mathrm{~m} / \mathrm{d}(96$ to $114 \mathrm{~m} / \mathrm{d})$ at $30 \mathrm{~km}$ altitude. If we narrow down our comparison to the observations close to the edge of the vortex (from 14 January 2001, onwards), we find a downward velocity due to diabatic cooling of $155 \pm 10 \mathrm{~m} / \mathrm{d}$ at an altitude of $30 \mathrm{~km}$. This is within the limits of the observations equal to the value reported by Schoeberl et al. (1992). By this means, our first-time observation of mid-stratospheric aerosol leads to an estimate of the dynamic properties within the Arctic polar vortex, which typically elude direct observation.

Acknowledgements. Meteorological analyses were provided by European Centre for Medium Range Weather Forecast (ECMWF), via the Norsk Institutt for Luftforskning (NILU), and by the National Centers for Environmental Prediction (NCEP). GOES observations were provided by National Oceanic and Atmospheric Administration (NOAA), via Space Physics Interactive Data Resource (spidr.ngdc.noaa.gov/spidr/). Rocket launch data were provided by European Space Operations Center (ESOC), of the European Space Agency (ESA). These contributions are gratefully acknowledged. Observations at Koldewey Station, Ny-Ålesund, were performed by AWI staff members K. Krüger and C. Wille as well as I. Beninga and W. Ruhe from impres GmbH. ARCLITE Lidar observations in Greenland were performed by the Søndrestrøm site crew and funded by the US National Science Foundation's Upper Atmospheric Research section under Cooperative Agreement ATM-9813556.

Topical Editor D. Murtagh thanks two referees for their help in evaluating this paper.

\section{References}

Arlt, R. and Guyssens, M.: Bulletin 16 of the International Leonid Watch: Results of the 2000 Leonid Meteor Shower, WGN, the Journal of IMO, 28, 191-204, 2000.

Beyerle, G., Deckelmann, H., Neuber, R., Rosen, J. M., Reimer, E., and Schoeberl, M. R.: Occurrence of solid particles in the winter polar stratosphere above the nitric acid trihydrate coexistence temperature inferred from ground-based polarization lidar observations at Ny-Ålesund, Spitsbergen, J. Geophys. Res., 106, 2979-2992, 2001.

Browell, E. V., Butler, C. F., Ismail, S., Robinette, P. A., Carter, A. F., Higdon, N. S., Toon, O. B., Schoeberl, M. R., and Tuck, A. F.: Airborne lidar observations in the wintertime Arctic stratosphere: Polar stratospheric clouds, Geophys. Res. Lett., 17, 385388, 1990.

Brownlee, D. E.: Cosmic Dust: Collection and research, Ann. Rev. Earth. Planet. Sci., 13, 147-173, 1985.

Ceplecha, Z., Borovicka, J., Elford, W. G., Revelle, D. O., Hawkes, R. L., Porubcan, V. and Simek, M.: Meteor phenomena and bodies, Space Sci. Rev., 84, 327-471, 1998.

Fiocco, G. and Grams, G.: Observations of the aerosol layer at $20 \mathrm{~km}$ by optical radar, J. Atmos. Sci., 21, 323-324, 1964.

Fleming, E. L., Chandra, S., Barnett, J. J., and Corney, M.: Zonal mean temperature, pressure, zonal wind, and geopotential height as functions of latitude, Adv. Space Res., 10, 11-59, 1990.

Fricke, K. H., Müller, K. P., Langer, M., Römke, K., and Lübken, F. J.: Visual and lidar observation of rocket induced effetcs in the 
upper atmosphere above Andøya on 25 January 1995, Proc. 12th ESA Symp. on European Rocket and Balloon Programmes and Related Research, European Space Agency, ESA-SP 370, 107112, 1995.

Gadsden, M. and Schröder, W.: Noctilucent clouds, SpringerVerlag, New York, 1989.

Hanson, D. R. and Mauersberger, K.: Laboratory studies of the nitric acid trihydrate: Implications for the south polar stratosphere, Geophys. Res. Lett., 15, 855-858, 1988.

Herber, A., Gernandt, H., Thomason, L. W., Leiterer, U., Nagel, D., Schulz, K.-H., Kaptur, J., Albrecht, T., and Notholt, J.: Continuous day and night aerosol optical depth observations in the Arctic between 1991 and 1999, J. Geophys. Res., 107, D10, 10.1029/2001JD000536, 2002.

Hofmann, D. J. and Rosen, J. M.: On the background stratospheric aerosol layer, J. Atmos. Sci., 38, 168-181, 1981.

Hofmann, D. J. and Rosen, J. M.: Balloon-borne observations of stratospheric aerosol and condensation nuclei during the year following the Mt. St. Helens eruption, J. Geophys. Res., 87, 11 039$11061,1982$.

Hofmann, D. J. and Rosen, J. M.: Condensation nuclei events at $30 \mathrm{~km}$ and possible influences of solar cosmic rays, Nature, 302, 511-514, 1983.

Hofmann, D. J., Rosen, J. M., Harder, J. W., and Hereford, J. V.: Balloon-borne measurements of aerosol, condensation nuclei, and cloud particles in the stratosphere at McMurdo Station, Antarctica, during the spring of 1987, J. Geophys. Res., 94, $11253-11269,1989$.

Hunten, D. M., Turco, R. P., and Toon, O. B.: Smoke and dust particles of meteoric origin in the mesosphere and stratosphere, J. Atmos. Sci., 37, 1342-1357, 1980.

Jackman, C. H., Considine, D. B., and Fleming, E. L.: A global modeling study of solid rocket aluminum oxide emission effects on stratospheric ozone, Geophys. Res. Lett., 25, 907-910. 1998.

Jackman, C. H., Fleming, E. L., and Vitt, F. M.: Influence of extremely large solar proton events in a changing stratosphere, J. Geophys. Res., 105, 11 659-11 670, 2000.

Jackman, C. H., McPeters, R. D., Labow, G. L., Fleming, E. L., Praderas, C. J., and Russell, J. M.: Northern hemisphere atmospheric effects due to the July 2000 solar proton event, Geophys. Res. Lett, 28, 2883-2886, 2001.

Jones, A. E., Bekki, S., and Pyle, J. A.: On the atmospheric impact of launching the Ariane 5 rocket, J. Geophys. Res., 100, 16 651$16660,1995$.

Junge, C. E., Chagnon, C. W., and Manson, J. E.: Stratospheric aerosols, J. Meteorol., 18, 81-108, 1961.

Kivi, R., Kyrö, E., Dörnbrack, A., and Birner, T.: Observations of vertically thick polar stratospheric clouds and record low temperature in the Arctic vortex, Geophys. Res. Lett., 28, 3661-3664, 2001.

Koop, T., Carslaw, K. S., and Peter, T.: Thermodynamic stability and phase transitions of PSC particles, Geophys. Res. Lett., 24, 2199-2202, 1997.

Larsen, N., Rosen, J. M., Kjome, N. T., and Knudsen, B.: Deliquescence and freezing of stratospheric aerosol observed by balloonborne backscattersondes, Geophys. Res. Lett., 22, 1233-1236, 1995.

Lucke, R. L., Korwan, D., Bevilacqua, R. M., Hornstein, J. S., Shettle, E. P., Chen, D. T., Daehler, M., Lumpe, J. D., Fromm, M. D., Debrestian, D., Neff, B., Squire, M., König-Langlo, G. and Davies, J.: The Polar Ozone and Aerosol Measurement (POAM III) instrument and early validation results, J. Geophys. Res.,
104, 18 785-18 799, 1999.

Manney, G. L., Sabutis, J. L., and Swinbank, R.: A unique stratospheric warming event in November 2000, Geophys. Res. Lett., 28, 2629-2632, 2001a.

Manney, G. L., Sabutis, J. L., and Swinbank, R.: Correction to "A unique stratospheric warming event in November 2000", Geophys. Res. Lett., 28, 4475, 2001 b.

Mateshvili, N., Mateshvili, G., Mateshvili, I., Gheondjian, L., and Avsajanishvili, O.: Vertical distribution of dust particles in the Earth's atmosphere during the 1998 Leonids, Met. Planet. Sci., 34, 969-973, 1999.

Mishchenko, M. I.: Light scattering by randomly oriented axially symmetric particles, J. Opt. Soc. Am., 8, 871-882, 1991.

Müller, K. P., Baumgarten, G., Siebert, J., and Fricke, K. H.: The new lidar facility at Esrange, Kiruna, Proc. 13th ESA Symp. on European Rocket and Balloon Programmes and Related Research, European Space Agency, ESA-SP 397, 129-134, 1997.

Müller, M., Neuber, R., Beyerle, G., Kyrö, E., Kivi, R., and Wöste, L.: Non-uniform PSC occurrence within the Arctic polar vortex, Geophys. Res. Lett., 28, 4175-4178, 2001.

Naujokat, B.: The stratospheric circulation during the northern winter 2000/2001, 8th Scientific Assembly of IAMAS, International Association of Meteorology and Atmospheric Sciences, Innsbruck, 2001.

Newman, P. A., Wilson, J. C., Ross, M. N., Brock, C. A., Sheridan, P. J., Schoeberl, M. R., Lait, L. R., Bui, T. P., Loewenstein, M., and Podolske, J. R.: Chance encounter with a stratospheric kerosene rocket plume from Russia over California, Geophys. Res. Lett., 28, 959-962, 2001.

Peter, T., Müller, R., and Crutzen, P. J.: The lifetime of leewaveinduced ice particles in the Arctic stratosphere: II. Stabilization due to NAT-coating, Geophys. Res. Lett., 21, 1331-1334, 1994.

Pinto, J. P., Turco, R. P., and Toon, O. B.: Self-limiting physical and chemical effects in volcanic eruption clouds. J. Geophys. Res., 94, 11 165-11 174, 1989.

Pruppacher, H. R. and Klett, J. D.: Microphysics of clouds and precipitation, 2nd ed., Kluwer Academic Publishers, Dordrecht, 1997.

Randall, C. E., Bevilacqua, R. M., Lumpe, J. D., and Hoppel, K. W.: Validation of POAM III aerosols: Comparison to SAGE II and HALOE, J. Geophys. Res., 106, 27 525-27 536, $2001 \mathrm{a}$.

Randall, C. E., Siskind, D. E., and Bevilacqua, R. M.: Stratospheric NOx enhancements in the southern hemisphere vortex in winter/spring of 2000, Geophys. Res. Lett., 28, 2385-2388, $2001 \mathrm{~b}$.

Rosinski, J. and Snow, R. H.: Secondary particulate matter from meteor vapors., J. Meteor., 18, 736-745, 1961.

Russell, P. B. and McCormick, M. P.: SAGE II aerosol data validation and initial data use: An introduction and overview, J. Geophys. Res., 94, 8335-8338, 1989.

Schoeberl, M. R., Lait, L. R., Newman, P. A., and Rosenfield, J. E.: The structure of the polar vortex, J. Geophys. Res., 97, 78597882, 1992.

Sheridan, P. J., Brock, C. A., and Wilson, J. C.: Aerosol particles in the upper troposphere and lower stratosphere: Elemental composition and morphology of individual particles in northern midlatitudes, Geophys. Res. Lett., 21, 2587-2590, 1994.

Solomon, S., Portmann, R. W., Garcia, R. R., Thomason, L. W., Poole, L. R., and McCormick, M. P.: The role of aerosol variations in anthropogenic ozone depletion at northern midlatitudes, J. Geophys. Res., 101, 6713-6727, 1996.

Thayer, J. P., Nielsen, N. B., Warren, R., Heinselman, C. J., and Sohn, J.: Rayleigh lidar system for middle atmosphere research 
in the Arctic, Opt. Eng., 36, 2045-2061, 1997.

von Zahn, U., von Cossart, G., Fiedler, J., Fricke, K. H., Nelke, G., Baumgarten, G., Rees, D., Hauchecorne, A., and Adolfsen, K.: The ALOMAR Rayleigh/Mie/Raman lidar: Objectives, configuration, and performance, Ann. Geophysicae, 18, 815-833, 2000.

Wilson, J. C., Loewenstein, M., Fahey, D. W., Gary, B., Smith, S. D., Kelly, K. K., Ferry, G. V., and Chan, K. R.: Observations of condensation nuclei in the Airborne Antarctic Ozone Experiment: Implications for new particle formation and polar stratospheric cloud formation, J. Geophys. Res., 94, 16437-16448, 1989.

Zhao, J., Toon, O. B., and Turco, J. P.: Origin of stratospheric nuclei in the springtime polar stratosphere, J. Geophys. Res., 100, 5215-5227, 1995. 